\title{
Federalismo y formación estatal en los antecedentes de la Revolución de la Costa. La Provincia de Santa Marta entre 1830 y 1842
}

\author{
Rigoberto Rueda Santos \\ Pontificia Universidad Javeriana, Colombia \\ rueda.r@javeriana.edu.co
}

\begin{abstract}
Resumen
Este artículo propone una interpretación acerca de la participación de la Provincia de Santa Marta en la Guerra de los Supremos desde los antecedentes configurados en la década anterior. Tras examinar las demandas del gobernador provincial a finales de 1839 que anticipan la aspiración federal, el ensayo se detiene en algunas de las tensiones presentadas entre las aspiraciones de los gobernantes provinciales y el poder central a lo largo de la década de 1830. El epílogo de esta situación es el pronunciamiento del cantón de Santa Marta y la reivindicación del sistema federal de gobierno al menos para las provincias de la costa Caribe que se agrupan bajo el fugaz Estado del Manzanares y que constituye el preámbulo a la Revolución de la Costa.
\end{abstract}

Palabras clave: Nueva Granada, federalismo, guerras civiles, Guerra de los Supremos, Provincia de Santa Marta, Estado del Manzanares.

\begin{abstract}
This article proposes an interpretation on the participation of the Province of Santa Marta in the so-called "War of the Supreme" from the background set in the previous decade. After considering the demands of the provincial governor in late 1839 that anticipate the Federal aspiration, the paper was halted in some of the tension presented between the aspirations of provincial governments and the central government over the decade of 1830 . The epilogue of this is the pronouncement of the canton of Santa Marta and the claim of a federal system of government at least for the provinces of the Caribbean Coast, which are grouped under the fleeting State of Manzanares and are the preamble to the Coast Revolution.
\end{abstract}


Key Words: New Granada, Federalism, Civil Wars, War of the Supreme, Province of Santa Marta, State of Manzanares.

\section{Introducción}

La emergencia de tendencias autonómicas de ciudades, Estados o "provincias soberanas" que buscan afirmar su independencia o unirse a los pueblos vecinos en una organización política nueva - bien sea confederal, federal o centralizada - es un proceso que se abre con la Independencia y configura una primera etapa de la formación estatal, prácticamente en el conjunto de países de Latinoamérica. La naturaleza de la nueva organización política será el gran motivo de pugna en el periodo siguiente, pero el papel del autonomismo provincial que emerge no se ha podido apreciar debido al descrédito posterior de los llamados "regionalismos" (Chiaramonte, "La formación" 144-150). Lo que se denomina federalismo es en realidad una expresión de las tendencias a unirse por parte de los pueblos que surgen como sujetos soberanos, pero su integración en una sola soberanía será fruto de un largo y complejo proceso, en ausencia de un verdadero marco nacional ${ }^{1}$. En ese sentido resulta central comprender la formación del Estado como el proceso por el cual "quienes lo forman logran superar una preexistente oposición de sus poblaciones y someter a los jefes políticos regionales" (López-Alves 43).

En el contexto de la tensión entre los esfuerzos realizados por la elite estatal neogranadina en pos de la centralización política y la oposición interpuesta por las fuerzas políticas provinciales se presenta el levantamiento de Santa Marta, simultáneo al de las otras provincias de la región, y denominado por sus gestores como la "Revolución de la Costa". La conjetura de partida en este trabajo es que el levantamiento entre 1840 y 1842 constituye la coyuntura de máxima tensión en el proceso de negociación del pacto político. En ese sentido, la Guerra de los Supremos configura un momento específico de la conflictiva construcción del Estado nacional respecto a las soberanías provinciales.

1 “[...] el supuesto de un marco nacional, en cuanto implica inexistentes fenómenos de tal dimensión -mercados, clases sociales, partidos políticos [...]-, contribuye también a la no percepción de esa realidad sustancial a la vida social y política de la época: que la pretensión de autonomía local -traducida inicialmente a través del crecido papel político del ayuntamiento- es expresión de una vida económica, social y política de esas limitadas dimensiones. De allí que los conflictos sean por lo común derivados ya de la voluntad de defender los intereses de una entidad autónoma frente a los de las autonomías vecinas y, sobre todo, frente a las pretensiones hegemónicas de la ciudad principal del territorio, ya de las discrepancias en definir la organización política que pudiera contenerlas a todas" (Chiaramonte, "Estado" 152,158-159). 


\section{Una tradición autonomista}

En los años noventa del siglo pasado se producen trabajos que integran el tema de la construcción estatal y nacional republicana, con la subsistente aspiración federal de las provincias y el papel de la llamada guerra de los Supremos en la Costa Caribe, su complejidad y las peculiaridades de su desenvolvimiento. Adelaida Sourdis ha planteado que la participación de las provincias de Cartagena, Santa Marta y Riohacha en las guerras de 1831 y de los Supremos en 1840 no son simplemente aventuras caudillistas lideradas por venezolanos, sino que principalmente constituyeron "frustrados intentos de lograr autonomía frente a Bogotá". La autora encuentra en los conflictos armados de 1831, 1840 y 1843 tres elementos comunes: "el espíritu federalista en contra de la república centralista"; "el particularismo de las antiguas provincias coloniales", y la afirmación de una subregión constituida alrededor de Barranquilla" $(158,199)$. Bell Lemus ha planteado que la resistencia de las provincias de la Costa ante "el nuevo orden institucional que la república trajo consigo" va a constituir uno de los grandes obstáculos para la formación del Estado nacional en la primera mitad del siglo XIX. La Guerra de los Supremos para el autor es una expresión radical del sentimiento regionalista surgido por razones económicas, políticas y culturales, sin perjuicio del desarrollo de un sentimiento nacional de pertenencia a la Nueva Granada (34-35).

Más que un sentimiento regionalista, la idea federal, que, sin renunciar a pertenecer a la Nueva Granada, se plantea como el sistema de gobierno más apropiado para las provincias del Caribe, es contemplada por una importante fracción de sus dirigentes políticos, muchos de los cuales se verán comprometidos en la guerra de $1840^{2}$. El federalismo de las provincias del litoral Caribe tiene ocasión de expresarse ya durante el golpe de Urdaneta. En marzo de 1831 el general Luque se levanta en Barranquilla y convoca un congreso constituyente de carácter federal para el departamento del Magdalena. La iniciativa de Luque es secundada por los generales Carmona en Ciénaga y Portocarrero en Santa Marta. Pese a que el restablecimiento del gobierno legal en Bogotá y el reconocimiento de las provincias a su autoridad hacen abandonar el proyecto,

2 Con la disolución de la República de Colombia y la institución del Estado de la Nueva Granada, el federalismo pervive débilmente en las provincias, "pero nutriéndose de las ambiciones y antagonismos locales y la desconfianza provincial del dominio de la ciudad capital, y contenido por el fenómeno muy transitorio de un estado de un solo partido y el narcótico de unas asambleas provinciales con unos poderes altamente limitados" (Gilmore 111). 


\section{FRONTERAS}

Ciénaga permanecerá como centro de las actividades federalistas a lo largo de la década de los años treinta ${ }^{3}$.

La misma inquietud por un cambio en el sistema de gobierno es la que se expresa dentro de la Provincia de Santa Marta a fines de 1839, un año antes del pronunciamiento que desata la guerra. En Ciénaga han comenzado por entonces los preparativos de conspiración y la agitación llega a la capital de la provincia. Por varios meses se esparce el rumor de que estallará una revolución en Santa Marta, lo que mantiene la alarma en la ciudad. En Ciénaga los rumores no son menores. Se habla, además, de un ataque por parte de Santa Marta. El gobernador, Pedro Díaz Granados, dispone no solo poner en guardia la tropa en Ciénaga, sino que se recurre a la Guardia Nacional auxiliar y cívica; Díaz Granados desestima las alarmas y los rumores como "obra de la chismografía"; más aún, cuando el jefe de Cantón y el propio general Carmona lo tranquilizan con la noticia de la total calma en dicha población. El gobernador se explica la situación como una campaña contra la ciudad de Santa Marta que busca arruinar el comercio de la ciudad y a sus habitantes (AGN, G 401, ff. 6r., 15r.-16).

A pesar de los mensajes de tranquilidad, la conspiración se promueve. Para la noche del domingo 3 de noviembre de 1839 se planea sorprender los cuarteles y demás puestos de la plaza, así como "asegurar" al gobernador. El complot se devela y el jefe militar y las tropas se ponen en guardia. A mediados del mismo mes, Díaz Granados informa al Secretario del Interior y Exteriores que han iniciado los procesos judiciales y que los principales sindicados y sospechosos se han dado a la fuga. Pese a que una relativa tranquilidad retorna a Ciénaga y Santa Marta, "el público permanece aun receloso" y las guarniciones están en vigilancia ${ }^{4}$.

Pero lo que tiene de relevante aquella comunicación del 12 de noviembre de 1839 es que ilumina las razones para la alteración del orden público y los motivos de la inconformidad regional, que siguen en juego en los pronunciamientos que se formularán un año después. Veamos en detalle los motivos que

3 Juan José Nieto propone en 1838 la adopción del sistema federal, con la esperanza de que, al aprobarlo, la Cámara Provincial de Cartagena lo presente al Congreso de la República (Bell 34-35); para el federalismo en Cartagena y particularmente la concepción de Nieto, véase Gilmore (113-119).

4 De acuerdo con la información recibida por el gobernador, Joaquín Anastasio Márquez, José Francisco Falques y Ramón Marín estarían comprometidos como cabecillas del levantamiento (AGN, G 401, ff. 04-015, 019-022). 
expone el gobernador provincial, que, sin duda, se conectan con las posteriores demandas por cambios en el sistema de gobierno.

\section{Las razones para un cambio en el sistema de gobierno}

En efecto, Díaz Granados funge aquí como vocero de toda la provincia, y, pese a aclarar que su propósito "no [es] tanto que se establezca el sistema federal propiamente dicho, sino de que se amplíen las facultades de las cámaras de provincia", aprovecha para plantear al gobierno central los que define como "los deseos" de todos los cantones de la provincia, y no solo de los de Santa Marta y Ciénaga.

El primer punto, sobre el que ya se habían realizado peticiones al Congreso, gira en torno a las facultades de la Cámara Provincial, y plantean claramente el disgusto de los pueblos de su provincia, "i acaso otros de la república",

Al ver frustradas las esperanzas que tenían de una buena administración local por medio de las cámaras provinciales, pues la experiencia de siete años les ha demostrado que como estas corporaciones, lo mismo que los gobernadores carecen de facultad para hacer llevar a cabo la mayor parte de los decretos que espiden éstas, de las cuales unos son suspendidos por el Poder Ejecutivo i otros pasan al Congreso en donde raras veces se aprueba uno que otro, i los demás se relegan al olvido. Asi es que las referidas cámaras son consideradas como mera ilución $i$ lo que en ellas se costea anualmente se tiene por perdido sin provecho alguno. (AGN, G 401, ff. 6r., 15r.-16)

Por otra parte, el sentimiento con que se ven desde la provincia las asambleas legislativas es de desprecio. Las esperanzas puestas en el Congreso se han visto defraudadas, su acción no satisface las expectativas de la Provincia:

Todos los años cuando se reúne el congreso se espera la reforma de las leyes malas, que solo esta esperanza hace que se sufran con paciencia, la codificación de

$5 \quad$ Es interesante la similitud con las preocupaciones de Cartagena. "A fines de 1839 todos los intentos y esfuerzos que habían hecho los dirigentes cartageneros, para sacar del estancamiento económico en que se hallaba tanto la ciudad como la provincia, no habían arrojado los resultados esperados. La sensación de que tal estancamiento se debía a la poca voluntad que el gobierno central tenía para ayudar a Cartagena era compartida por muchos. En noviembre de ese año la Cámara Provincial le presentó al Congreso una lista de 28 medidas, entre las cuales figuraban el libre cultivo del tabaco, el establecimiento de una casa de moneda, la imposición de nuevos impuestos sobre el Canal del Dique para su rehabilitación" (Bell 35). 


\section{FRONTERAS}

de la fistoria

las distintas leyes vigentes sobre un mismo asunto que tanto embarazan la marcha de la administración, i la espedicion de otras de que se carece i que son de una importancia vital; pero cierra sus sesiones sin haber hecho nada de lo que se esperaba, i se cree que sus trabajos no compensan las gruesas sumas que cuestan a la nación. Y además se dice que los actos legislativos regularmente protejen a las provincias del interior con perjuicio de las de la costa. (AGN, G 401, ff. 6r., 15r.-16)

El otro motivo de queja es el de la inseguridad en que este mantiene la plaza de Santa Marta. El puerto y la ciudad están a expensas de quien quiera tomarlos, pues la ciudad no dispone de fuerza alguna para defenderse, y sus habitantes quedarían expuestos:

No solo los intereses de los habitantes, i los nacionales, sino los de los comerciantes del interior i del extranjero que por aquí transitan a la merced de cualquier pirata ó revoltoso que se proponga saquear la ciudad. (AGN, G 401, ff. 6r., 15r.-16)

El Congreso no ha considerado, hasta el momento, la representación que le ha dirigido la Cámara Provincial, en la que pide encarecidamente la fortificación de la plaza.

Una razón de inconformidad "todavía mayor" se presenta contra el Tribunal de Apelaciones del Magdalena, con sede en Cartagena. A los Tribunales de Justicia "se les tiene como lo más defectuoso que ecsiste en el actual sistema de gobierno". Las actuaciones de la corporación se perciben claramente como en detrimento de la propia administración provincial y sus funcionarios:

Los abogados que antes eran objeto de respeto y aprecio, son mirados como unos estafadores públicos, i la conducta de algunos de los que han compuesto el tribunal de apelaciones del Magdalena, han desacreditado en grande manera esta corporacion i la ha hecho temible y odiosa. (AGN, G 401, ff. 6r., 15r.-16)

La situación constituye una traba al propósito de construir un aparato administrativo nivelasen los ámbitos locales. La perspectiva de quedar en la ruina, ya sea con las multas impuestas por el tribunal, o de ser despojado de todo por parte de los abogados, en caso de sufrir un juicio en Cartagena, hace que nadie en la provincia quiera asumir cargos en la administración:

Nadie quiere ser juez ni alcalde en esta provincia, i por lo común el motivo no es otro, sino que ya se da por hecho que el que fuere queda arruinado, bien con las multas que le impone el tribunal o bien, por que en caso de tener que ir a Cartagena a sufrir un juicio, por bien que salga de él, vuelve a su casa a trabajar de nuevo 
obligado por la necesidad en que lo han dejado los abogados que le han quitado todo cuanto tenia. (AGN, $G$ 401, ff. 6r., 15r.-16)

Por otra parte, el descontento a propósito de la circulación de monedas es general. No hay un sistema confiable y generalizado para establecer su calidad. El problema está en la calificación del circulante, dado que los plateros o peritos nunca están de acuerdo, sus valoraciones nunca coinciden, la regla a la que toda transacción queda sujeta es a la del capricho de cada cual: "El comercio se resiste a recibir la moneda cortada i no hai mas arbitrio que proceder con prudencia". La anarquía en la circulación de monedas afecta tanto al comercio como a la propia recaudación fiscal, y toda disposición parece inútil.

El último problema señalado es el de la miseria general en que se hallan los pueblos del interior de la provincia, como se expresa en la limitada circulación de moneda. En el cantón de Valledupar es frecuente el intercambio de unos artículos por otros, "aun de aquellos que se consumen diariamente".

Díaz Granados alude a las cuestiones que están en la base de la aspiración federal, da cuenta de las configuraciones que en el largo plazo explican el desarrollo de la llamada "Guerra de los Supremos" en la costa Caribe. En los siguientes apartados veremos con detalle algunos de esos procesos que en el transcurso de la década de 1830 constituyen los antecedentes de la Revolución de la Costa, pues expresan las tensiones y límites de la centralización política y explican la demanda autonomista.

\section{La Provincia y el poder central. Mediaciones, forcejeos y tensiones}

El Estado de la Nueva Granada se constituye por Ley Fundamental del 17 de noviembre de 1831. La Convención Nacional sigue sesionando hasta la promulgación de la nueva Constitución, en marzo del año siguiente. Una de sus novedades es el regreso a la organización en provincias, las cuales se dividen en cantones. Las leyes sobre régimen político, adoptadas en 1832 y 1834, definen al gobernador como instancia del poder ejecutivo en las provincias, ratifican su dependencia del poder ejecutivo y su calidad como agente del mismo, y le adjudican el cuidado de la tranquilidad, el orden, la seguridad y la garantía de los derechos "de los ciudadanos y habitantes", la ejecución de la constitución y las leyes y de las sentencias judiciales, y de "la prosperidad de la provincia". El gobernador debe convocar las sesiones anuales de la Cámara Provincial, y en su instalación presentar un informe sobre el estado de la provincia. Junto con esta obligación, tiene establecidas como funciones la del 


\section{FRONTERAS}

patronato eclesiástico, la promoción de la instrucción pública y de los recaudos fiscales, y las visitas anuales en la provincia (Martínez).

El control del Ejecutivo a través de las secretarías de Hacienda, de Guerra y Marina, y del Interior y Relaciones Exteriores es tal que la gobernación cumple más un papel de intermediación con poco margen de autonomía ${ }^{6}$. Esto es claro en los casos de solicitudes de empleo, de permisos y licencias, de naturalización o nacionalización, de reclamos de los comerciantes, de jubilaciones, etc., que deben solicitarse mediante representaciones ante la instancia central, y ante las cuales el gobernador solo expone su parecer cuando les da traslado. Igual ocurre con los casos de los estados de cuenta de cada una de las rentas, pues la gobernación los remite para su aprobación en Bogotá. El gobernador también recibe comunicación de disposiciones inconsultas, para ser cumplidas o circuladas, principalmente en materia de hacienda; igualmente, acusa recibo de órdenes que, de inmediato, transmite a la oficina pertinente y ejecuta órdenes del gobierno central para adelantar exportaciones.

El poder discrecional del Ejecutivo y las instancias centrales también se mantiene respecto a la legislación que, dadas sus ambigüedades a la hora de sus aplicaciones locales, genera permanentes dudas y consultas. A expensas de los intereses de la provincia, el Ejecutivo, a través de sus secretarías, es quien decide sobre la correcta interpretación de la ley, de manera que aunque el gobernador de turno toma una decisión en primera instancia, normalmente consulta al gobierno nacional en espera de que sea aprobada o reformada la medida que inicialmente ha dispuesto ${ }^{7}$. Los remates sobre bienes públicos, por

6 Los niveles de control llegan hasta la desaprobación, por considerar excesivo el gasto, de la compra de cuatro libros para la oficina del presidio urbano, determinado por la Junta de Hacienda de la Provincia, no obstante estar amparada la decisión en el decreto reglamentario que ordena llevar cuatro libros, sin especificidad del tamaño u otra calidad (AGN, G 397 , f. $24 v$.).

7 En el caso de la decisión del gobernador de eximir del derecho de porte a los envíos oficiales de dinero que se hiciesen por correo. La disposición proviene de la diversa aplicación que los funcionarios hacen de los decretos y leyes en la materia. El estafetario de Chiriguaná cobra el porte de correos a la correspondencia oficial, mientras que en los demás cantones no se hace, no obstante que el dinero cobrado es remitido a la Tesorería de Rentas. El punto reside en la interpretación de una ley de 1835 que deja exenta de pago de derechos la correspondencia oficial de las cámaras provinciales. La gobernación interpreta que lo anterior cubre el envío oficial de dinero procedente de los cantones de la provincia que fuese remitido a las tesorerías de la respectiva renta, y por ello, en aras de dictar una norma general, y considerando la escasez de fondos de las distintas corporaciones, toma la decisión, que el gobierno descalifica como errónea. Por el contrario, se ratifica que los caudales remitidos a las rentas provinciales están sujetos a pagar el derecho correspondiente, deroga la resolución del gobernador y exige el pago retroactivo por parte de las administraciones que hubiesen dejado de pagar (AGN, G 397, ff. 717v. -718r.). 
ejemplo, tienen aprobación final por el gobierno central, el cual define si un remate tiene lugar, ordena la devolución de los expedientes o las rectificaciones para hacer de nuevo la operación.

Pueden, no obstante, citarse casos en que las secretarías consultan a las instancias provinciales. Pero en este punto la actitud de los funcionarios es difícil de explicar. A fines de 1837 la Junta de Hacienda de la provincia, tras una consulta de la Secretaría de Guerra a propósito de algunas disposiciones, se limita a señalar que, a pesar de tener fundadas razones para hacer observaciones, se abstiene de hacerlas "para dar una nueva prueba de subordinación al gobierno, cuyas determinaciones siempre ha mirado con respeto" (AGN, G 397, f. 721r.). A propósito de la expedición de un nuevo arancel para el cobro de derechos de importación y de alcabala de puertos para la Aduana, que debería comenzar a observarse en diciembre de 1839, y pese a que desde el mes de agosto el gobernador establece una comisión para revisar el vigente y hacer las recomendaciones que se considerasen, la comisión, compuesta por dos comerciantes y el administrador de aduana, finalmente no cumple (AGN, $G 400$, ff. 760v.-761r.).

Usualmente, los proyectos remitidos a la Provincia para su estudio no reciben críticas o debate. Es también el caso del proyecto de código de instrucción pública, puesto en discusión por el gobierno a principios de 1834, y que no recibe objeción alguna, pese a la consulta que el gobernador hace de la "opinion de algunos inteligentes en la materia"; tan solo el Obispo manifiesta intención de dirigir sus opiniones al Secretario (AGN, G 390, f. 485). Frente a la ley orgánica del régimen político de las provincias, expedida el 19 de mayo de 1834, el gobierno provincial no presenta objeciones, la ley no concita resistencia ni reclamo alguno, y solamente se formula un par de dudas puntuales ${ }^{8}$.

Las consultas del gobierno central a la Provincia constituyen más bien un mecanismo de legitimación de las leyes o disposiciones en cuestión, pues connotan cierto nivel de participación por parte de las autoridades provinciales. Tal es el caso de la invitación de la Secretaría de Hacienda para que la gobernación enviase propuestas en algunos ramos de la administración a fin de

La primera se refiere a la definición de facultades de las diferentes instancias de la administración, pues hay materias en que las asambleas electorales, las cámaras de provincia y la gobernación parecen tener la misma competencia, o se pide la especificación de la autoridad ante la cual deben prestar juramento los empleados de los cantones, dadas las distancias de ellos. El segundo aspecto es el de las rentas provinciales (AGN, G 390, ff. 917- 919). 


\section{FRONTERAS}

mejorar los ingresos del tesoro nacional ${ }^{9}$. En ocasiones se trata de consultas en las que se pide informes para optar decisiones legales, como en marzo de 1834, cuando se solicita hacer observaciones al proyecto de código penal. En este sentido se inscribe la consulta hecha a gobernadores, cámaras de provincia y concejos municipales a mediados de 1838, para la organización de los establecimientos de castigo en las provincias (AGN, G 390, ff. 477, 483; 398: $32 v$.). La participación, así sea en el nivel de consulta, es un tipo de vinculación que hace nacional la ley en trámite.

Entre tanto, los casos de iniciativa legislativa desde la Provincia giran principalmente en torno a los temas fiscales. En repetidas ocasiones la gobernación solicita al Congreso un decreto que establezca un arancel para el cobro de los derechos parroquiales y de estola, basando la petición en los abusos que cometen los curas en su cobro; el vigente por entonces no ha sido modificado en veinte años. Concebido para la ciudad capital, se aplica a toda la provincia. Esta falta de adecuación facilita el abuso y los excesos que precisamente se quieren corregir. Desde 1835 se presentan dos proyectos de arancel: uno elaborado por la Cámara Provincial y otro por el obispo de entonces, José Ma. Esteves, ante los que el gobierno central guarda silencio (AGN, G 397, ff. 602v. - 603r.).

En el ámbito del gasto público, son varios los terrenos en los que las sucesivas administraciones provinciales forcejean con el gobierno central por la asignación de dineros del tesoro público. La Provincia demanda mayor participación del tesoro nacional en los gastos que conlleva la administración pública. La visita a la provincia plantea una de esas materias en que se reclama la participación de las rentas nacionales, dado que debe hacerse a costa del gobernador sin que los pueblos resultasen gravados en absoluto. Pero las visitas implican el desplazamiento de otros funcionarios, y en 1834 el gobernador Gómez solicita que la Tesorería general asuma estos viajes como gastos extraordinarios, pues al fin y al cabo, argumenta, con ellas se busca mejorar el servicio público y "el adelantamiento y prosperidad de la provincia". Finalmente, todas las iniciativas y propuestas en esta materia son denegadas, y no se decreta abono

9 En octubre de 1831 la gobernación propone tres medidas: $1^{\circ}$ Permitir el ingreso de aguardientes extranjeros que no perjudiquen a los destiladores del país, como el de uvas; su ingreso sería en prueba y se distribuiría a través de estanquillos de tabaco; $2^{\circ}$ Estancar los naipes y la pólvora, o imponerles dobles derechos de introducción; y $3^{\circ}$ Gravar los pasaportes tanto para ultramar como para el interior, pero diferencialmente a extranjeros que a nacionales (AGN, G 386, f. 565). 
o indemnización alguna ni por el Congreso ni por el Ejecutivo (AGN, G 391, ff. 218-219).

En el interés por obtener recursos del gobierno central, a fines de 1836 se demanda que éste satisfaga los gastos necesarios a fin de "poner la plaza en estado de defensa", alegando que se mantiene aún la inminencia de una invasión a raíz de la detención del procónsul inglés en Panamá. En Santa Marta ya se han tomado algunas medidas, pero se espera que las pague el tesoro nacional, a lo que la Secretaría de Hacienda contesta que no considera de su competencia este gasto. En el año económico que comienza en septiembre de 1838, para citar otra situación, se recortan los gastos de escritorio y del alquiler de la casa donde despacha la gobernación. En esta materia la Secretaría es intransigente y hace un llamado a que se observe mayor economía (AGN, $G$ 398, ff. 472v.-473r.).

Igual ocurre con las leyes de gasto público que se promulgan cada año. En la sancionada en junio de 1836 se dejan de considerar los rubros por concepto de dietas y viáticos de los diputados de la Cámara provincial y se prohíbe que estos gastos se hagan contra el Tesoro. Sin embargo, el gobernador solicita el pago con fondos públicos, en razón de que el tesoro provincial está "exhausto", pero la Secretaría de Hacienda termina exigiendo un informe sobre los destinos de las rentas, para establecer si, efectivamente, se han realizado "escrupulosamente" (AGN, G 394, f. 753). La demanda por que el tesoro nacional asuma los costos de funcionamiento de la Cámara será permanente, dada la precariedad de los fondos para garantizarlo. Esta situación es crónica. Siempre se tiene que tomar dinero de otras cuentas para el pago de dietas y viáticos y los gastos de escritorio; unas veces de las de caminos; otras, del hidráulico, tal como ocurre en 1836 y 1837, pero algunas rentas tienen exclusiva aplicación, y no se puede disponer de ellas. En ocasiones, con la anuencia del gobernador, se recurre a los gastos extraordinarios para cubrir los costos (AGN, G 389, f. 836). En 1839 se pretende que el gobierno nacional asuma el alquiler de una casa para las sesiones de la Cámara, pues las existencias de las rentas provinciales lo impiden; aún así, no se consiente el gasto ${ }^{10}$.

10 Los gastos de arriendo de un local para las sesiones no están contemplados; desde 1832 las reuniones de los diputados se hacen alternativamente en una sala del Colegio Nacional, por consentimiento del rector, o en casa de algún particular que la presta gratuitamente (AGN, G 400, ff. 481v.-482r.). 


\section{FRONTERAS}

Así mismo, los miembros de la Cámara Provincial resienten las medidas del ejecutivo al suspender muchos de los decretos expedidos en sus sesiones. Entre ellos, los relativos al establecimiento de la Sociedad de Amigos del País, que se instala en noviembre de 1834 en desarrollo de las atribuciones de la ley orgánica de provincias de mayo de 1834 (AGN, G 391, ff. 858-860; 1055-1065). A través de la Sociedad se expresan, igualmente, los intereses de las elites y su proyecto para la Provincia. Sin negar el papel regulador de la administración central, desde la Sociedad se advierte sobre el exceso de intervención y el abuso de sus facultades restrictivas. Un argumento central es que en muchas de las materias objeto de deliberación de una Cámara los diputados provinciales tienen mayor conocimiento que los funcionarios de la administración central, carentes estos últimos de antecedentes sobre tales asuntos. Por tanto, se argumenta, son los diputados los llamados a "hacer la felicidad del territorio de su domicilio". Así mismo se reivindica el poder municipal como el instrumento para la prosperidad de los pueblos y garantía de que las libertades públicas se hagan reales y positivas, y se reclama con ello la facultad de dirigir los negocios locales (El Amigo, 30 de noviembre de 1835,4$)$.

Los diputados a la Cámara insistirán en la poca importancia que, aparentemente, tienen los resultados de su trabajo para el gobierno central. Sus iniciativas tropiezan con la suspensión de muchos de sus decretos y disposiciones, para lo que aducen confusión en sus atribuciones y desborde de competencias. Pero además de que los decretos promulgados deben ser aprobados por el legislativo, en los casos en que el trabajo represado en las oficinas de la gobernación hace tardar su envío, y este coincide con la reunión del Congreso en marzo, las decisiones tomadas por la Cámara simplemente no tienen oportunidad de ser consideradas ${ }^{11}$.

\section{Las dificultades para la provisión de cargos públicos}

Un problema crónico que enfrenta la administración y la hacienda públicas es el de la provisión de cargos, lo cual afecta la constitución de un aparato burocrático local. Por lo regular, las personas propuestas rehúsan el ofreci-

11 Ordinariamente las sesiones de la Cámara de Santa Marta se llevan a cabo entre septiembre y octubre de cada año, de manera que solo en el período legislativo del siguiente año los proyectos pasan al Congreso, siempre y cuando se notifiquen con tiempo. Por ejemplo, los decretos expedidos en octubre de 1832 apenas se notifican en julio de 1833. La situación se presenta de nuevo con el envío de la totalidad de decretos aprobados en las sesiones de 1834, cuyo examen se pospone hasta comienzos de 1835 (AGN, G 389, f. 571). 
miento y aún el nombramiento. La documentación permite escudriñar como razones principales los bajos sueldos y el desestímulo producido por las escasas oportunidades de ascenso ${ }^{12}$. Tan poco apetecidos son los cargos públicos que, en ocasiones, el gobernador, al presentar las ternas al gobierno central, señala expresamente el candidato que está dispuesto a aceptar el nombramiento. Sea el caso que fuere, las ternas no cumplen, en la práctica, sino un papel formal ${ }^{13}$.

Son profusas las ocasiones en que se tiene que informar al gobierno central el poco interés o lo poco atractivo que resulta en la Provincia encontrar quien asuma los pequeños cargos o empleos en las parroquias, por "lo mesquino de sus productos y las dificultades que se tocan para hallar hombres a propósito" sellado (AGN, G 398, ff. 305v.-307r.).. La queja proviene del jefe político del cantón de Chiriguaná, quien en agosto de 1838 encuentra que en sus distritos parroquiales no hay quienes quieran ser nombrados para la recaudación de rentas nacionales, función que abarca la recaudación - o colectura de recaudación - y la venta de papel sellado ${ }^{14}$.

Otro problema resulta de los nombramientos interinos que son provistos por el gobernador, pues, de conformidad con las disposiciones vigentes, el sueldo de un cargo en interinidad equivale a las $2 / 3$ partes del sueldo asignado en propiedad. Desde la gobernación se advierte al gobierno central sobre las consecuencias que tiene la baja remuneración de los cargos de hacienda de

12 Desde 1831 se registra una tendencia a la reducción de sueldos, el pago con retraso o su pago parcial, que afecta tanto a los empleados de Hacienda y los civiles como al personal militar. Las dificultades que aquí se relacionan no tienen en cuenta los tipos de régimen salarial (empleos de sueldo fijo y por porcentaje) ni las iniciativas de aumento.

13 El caso en que el nombrado no acepta la designación también ocurre con cargos de importancia: en mayo de 1833 la Cámara de la Provincia tuvo que nombrar nueva terna para el cargo de Fiscal del Tribunal del Distrito del Magdalena, pues el designado no acepta la plaza; el nombramiento como gobernador de la Provincia es denegado por Luis Bermúdez a fines de 1836 .

14 Inicialmente el jefe político piensa en obligar a los alcaldes a que cumpliesen dicha comisión que, además, significa correr con el pago del papel sellado y demás aspectos concernientes a la recaudación misma, pero la iniciativa no prospera, pues no se contempla en la ley que los alcaldes de los distritos parroquiales se encarguen de la administración de rentas nacionales. Dado que estos recaudadores son nombrados por el Administrador de recaudación del cantón, quien debe exigir fianza por la responsabilidad en el manejo, la única solución es que tal administrador redoble esfuerzos para encontrar a quien encargar de la recaudación en las parroquias, a fin de garantizar los ingresos del erario y la provisión de papel sellado (AGN, G 398, ff. 305v.-307r.). 


\section{FRONTERAS}

nivel cantonal, sobre todo cuando se trata de casos temporales, como el de las suspensiones, donde es más difícil encontrar quien admita el cargo.

La organización de las administraciones subalternas de recaudación encuentra dificultades por el poco estímulo que representaba para los comisionados el porcentaje que se les ha asignado. Los empleos de administradores de recaudación se reciben a disgusto por su poca rentabilidad. En la década de los años treinta esto es característico en lo que respecta a la tesorería provincial. El asunto reside en que el trabajo no tiene una compensación equivalente, y de este modo no es fácil encontrar "hombres de bien" que se hagan cargo del trabajo, que es bastante, según señala el administrador de recaudación. La administración tiene problemas para encontrar en cada parroquia sujetos capaces de desempeñar el puesto debidamente, por la escasa remuneración del cargo. El administrador debe sustituir a los que se niegan por quienes voluntariamente quieran aceptarlo. Lo producido es tan poco que no alcanza a recompensar los gastos indispensables que deben hacerse, ni a remunerar los trabajos en que se incurre. Los administradores de recaudación están establecidos para cada cantón, pero en estos años, en realidad, solamente funciona por separado el de Plato; el de Santa Marta hace circuito con el de Tenerife y el administrador en Valledupar tiene a su cargo el de Chiriguaná (AGN, $G$ 388, ff. 501v.-506).

La provisión de otros cargos tiene mayor dificultad, sobre todo tratándose del nivel cantonal, tal como ocurre con el nombramiento del Registrador de Instrumentos Públicos y Anotador de Hipotecas del cantón de Chiriguaná, donde, tras un primer ofrecimiento hecho por el gobernador - que ninguno de los nombrados quiso aceptar-, el gobernador presenta una nueva terna, sin que el jefe político del cantón le pueda asegurar que alguno fuese a admitir el empleo. La anuencia a tomar este tipo de cargos la explica el funcionario por el escaso monto del salario ofrecido, o, en palabras del gobernador, por "la general repugnancia que hay a causa de que sus productos quizá no alcanzan ni aún para los gastos de escritorio" (AGN, GV 208, ff. 406 - 407).

Tampoco es mayor el interés de los pobladores en ser colectores de diezmos comunales. En la parroquia de Remolino el alcalde se queja, a mediados de 1838 , de no encontrar vecino alguno que quisiera encargarse como colector comunal. Las justificaciones esgrimidas son dos: por no ser de carácter obligatorio y por no tener modos de presentar la fianza exigida por la ley. De fondo, los bajos ingresos de la renta, de los que depende el honorario, son el principal 
disuasivo. Aún los nombrados expresamente por el Consejo Colector Comunal se niegan a asumir, de modo que el alcalde resulta comisionando a los jueces parroquiales para el recaudo de estos derechos ${ }^{15}$.

El Cantón de Valledupar es particularmente apático. Su jefe político tiene dificultad para nombrar alcaide de la cárcel de la ciudad, dado que allí se presentan muy pocos a este servicio en razón del escaso sueldo del cargo; cuatro personas a quienes se les ha ofrecido han rehusado. La situación lleva al jefe político a consultar sobre si puede obligar a los ciudadanos a hacer este servicio, iniciativa que es negada por el despacho del Interior. Tampoco el alcaide ha podido conseguir carcelero, por lo bajo del sueldo. La situación propicia que el 8 de mayo de 1836 se presente una fuga general de presos. Cuando se necesitó proveer el cargo de Registrador de Instrumentos Públicos y Anotador de Hipotecas del mismo, después de ser rechazado dos veces por individuos que no aceptaron ser nombrados, el gobernador presenta una nueva terna, en la que expresamente recomienda a una persona. Similar situación se presenta cuando se debe proveer el cargo de colector de diezmos de la ciudad y los nombrados no aceptan, de modo que el gobernador tiene que presentar una nueva terna recomendando explícitamente a una persona, generalmente vinculada ya a la administración en algún cargo (AGN, GV 208, f. 231; G 394, ff. 941-942).

Lo cierto es que las disposiciones y previsiones de la ley siempre resultan desbordadas por las condiciones particulares de las parroquias, su pobreza y la posibilidad real de encontrar encargados. En Chiriguaná, por ejemplo, para la asignación de sus cargos, los empleados o administradores no presentan fianzas sobre bienes muebles, tales como casas o haciendas, dado que las únicas fincas raíces que hay son casas de paja; allí se admiten como fianza los bienes semovientes (AGN, G 398, ff. 55v.-62r.).

Un ámbito en el que no puede dejar de registrarse la dificultad para el establecimiento de un aparato burocrático es el de los jefes políticos de

15 La legislación del 19 de mayo de 1834 dispone que las Cámaras provinciales, los concejos municipales y provinciales, nombren los tesoreros y recaudadores de sus respectivas rentas asignándoles una renta fija a un tanto por ciento de lo recaudado. La misma ley señala la posibilidad de recurrir al sistema de arrendamiento para el caso de las rentas provinciales, comunales y municipales. Mantener las rentas en administración o darlas en arriendo debe ser resuelto por cada corporación de acuerdo con las circunstancias. Por otra parte, la ley de mayo de 1836 dispone que las cámaras, concejos municipales y comunales reúnan en una sola persona los cargos de tesorero y recaudador de rentas donde se pudiese (AGN, G 398, ff. 29v.-30). 


\section{FRONTERAS}

Cantón ${ }^{16}$. Dicho ambiente es de tal discrecionalidad que en 1832 el gobernador declara no haber encontrado un individuo "de su parecer" para ser nombrado, y la determinación se pospone por años ${ }^{17}$. Por lo demás, conseguir un desempeño adecuado de estos funcionarios es difícil, debido, según lo explica un gobernador, a que el cargo se admite con desagrado por las "molestias y disgustos" que proporciona (AGN, G 398, ff. 256, 780). En efecto, estos funcionarios no gozan de renta alguna por parte de los fondos municipales, de modo que tienen que buscar sus ingresos en otras actividades, lo que les demanda tiempo e interés que sustraen del cumplimiento pleno de sus funciones administrativas. La ausencia de un sueldo que compensase sus tareas parece justificar la falta de exactitud en todos sus informes (AGN, $G 400$, f. 1098).

Varios gobernadores de la Provincia coinciden en plantear como una condición para la consagración de los jefes políticos a los deberes públicos el darles una asignación a cargo de las rentas nacionales. En octubre de 1833 se propone que el período del jefe político del cantón de Santa Marta fuese de 4 años, al igual que para otros cantones donde el jefe político contara con sueldo, y de un año para los cantones sin sueldo. Aunque la propuesta cuenta con el respaldo del gobernador Gómez, no tiene éxito en el legislativo (AGN, G 389, f. 984). Díaz Granados volverá sobre la idea en octubre de 1839, al plantear ante los diputados a la Cámara que con un sueldo asignado el tiempo en el cargo podría extenderse y se nombrarían individuos de más capacidad:

Os lo dije el año pasado y ahora os lo repito, que los jefes políticos no se entregan a despachar los negocios oficiales con aquella asiduidad que demanda el importante puesto que ocupan, que muchas veces las personas que desempeñan aquellos destinos no son inteligentes aunque honrados, que en ocasiones pasan estos empleos en un año, de unas manos a otras; que en si es odioso el cumplimiento de sus obligaciones y por conclusión, es preciso no nos alusinemos creyendo que sus

16 La figura del jefe político de cantón es establecida en la Ley sobre Organización y Régimen de las Provincias, de mayo de 1834. Se concibe, entonces, como agente inmediato y subordinado al gobernador de la provincia y como agente en el gobierno de los cantones en que estuviese dividida. Véanse la Gaceta de la Nueva Granada, 142, del 15 junio de 1834, y 143, del 22 Junio de 1834 (cit. en Martínez 28).

17 Así ocurre en Tenerife para el nombramiento de jefe político en 1832. Habiéndose hecho "imposible" nombrar como jefe político a ningún vecino, por falta de "sujetos aparentes", corresponde, a comienzos de 1834, al de Santa Marta, José Ignacio Díaz Granados, asumir simultáneamente dicha jefatura. Entre tanto, José Manuel Martínez completa tres años consecutivos como jefe político del cantón de Valledupar (AGN, G 388, ff. 661). 
tareas domésticas y en donde les va el cuidado de sus intereses y la educación de sus familias, los posponen por funcionar en unos puestos, que por gajes y recompensa, solo toman en retorno sinsabores y disgustos (AGN, G 400, f.1095).

\section{Dispersión y ambigüedad en la legislación}

Son al menos dos los ámbitos donde la dispersión legislativa hace estragos a la hora de configurar un aparato administrativo que responda a un orden central. Por una parte, la legislación acerca de las importaciones que resiente la Aduana de Santa Marta y, por otra, la ausencia de disposiciones claras y fijas respecto a la circulación de monedas, que en la provincia samaria afecta distintos ordenes administrativos, y que es señalada específicamente por el gobernador Díaz Granados en su correspondencia de 1839. Antes de considerar los problemas en la legislación de importaciones, detengámonos un momento en el tema de la moneda.

No obstante que desde 1828 la ley ordena el recibo de toda moneda que no fuese falsificada, la gobernación llega a calificar de "escandalosa" la arbitrariedad con que se rehúsa admitir la moneda macuquina en la Provincia. El simple capricho obstruye la circulación por su valor nominal, y a cambio se le da una calificación según cada cual. Al menos desde 1833 las autoridades evidencian el disgusto y desazón entre el público que ha comenzado arbitrariamente a rechazar toda moneda, sin distinguir entre falsas y legítimas. No obstante, cuando el gobernador le señala al Secretario de Hacienda la necesidad urgente de una ley que arreglase el sistema monetario, desde Bogotá se desestima la gravedad de los hechos ${ }^{18}$. Durante 1837 se desatan numerosas controversias entre el público usuario, que por la desconfianza las rechaza. Los soldados de las tropas veteranas son los primeros en suscitar desavenencias, pues su pago se los suministra el Tesoro y es el dinero con que compran (AGN, G 399, ff. 715v.-717v.).

El desorden en la recepción de la moneda macuquina se hace inmanejable e involucra a todas las monedas de plata "de talla menor", por la ambigüedad

18 De acuerdo con el informe de la Casa de la Moneda de Bogotá, la alarma no tiene fundamento: de 150 pesos que han ingresado a la Casa en reales de cordón que se suponen falsos, se encuentra que solo 14 realmente lo son y todos los demás han sido acuñados en Casas del Estado, por lo que se concluye que la mayor parte de los reales que provocan la desconfianza no deben ser falsos. Por otra parte, los reales que han sido acuñados en la Casa de la Moneda de Popayán tienen algunas imperfecciones. Es posible que sean estas las monedas que circulan en Santa Marta y que están provocando la indisposición (AGN, G 389, ff. 436-437). 


\section{FRONTERAS}

en el reconocimiento de su legitimidad. En la base de la situación está la mala calidad de las monedas y el reconocimiento general de que se han admitido en el país sin ningún control. La macuquina antigua mejicana es una de las que el público no admite. Aún con las monedas consideradas legítimas, como en el caso de las acuñadas entre 1815 y 1821 , hay resistencia a recibirlas, por estar ligadas con cobre. Ni los jueces ni la policía pueden ejercer su autoridad, porque cada cual admite las monedas que le gustan. Las autoridades provinciales prevén incluso desórdenes en los mercados, pues, a su juicio, los más pobres son los más perjudicados y puede acrecentarse su desesperación (AGN, $G$ 400, f. 432v., 435-436).

La circulación de monedas falsas afecta la misma administración pública, pues una oficina recibe como moneda legítima la que otra puede considerar falsa. Al administrador de Aduana la Tesorería le rechaza algunas monedas y la administración de correos de Cartagena le confisca una cantidad que ha remitido (AGN, G 389, f. 450). Para el funcionario, el problema no está en la variedad de monedas, sino en la cantidad de monedas falsas o que están rotas o gastadas, y en la falta de reglas claras para decidir su validez en los casos que se rechazan. Hay tantas reglas de calificación de monedas como personas juzgando, con el agravante de que cambian de parecer de un día para otro; de ahí la arbitrariedad de unos en el recibo de las monedas y el disgusto de todos (AGN, G 400, ff. 437v.-438r.). El mismo problema se presenta en los cantones. El estanquero de tabacos de Valledupar se queja de haber recibido monedas como de buena circulación que le han sido devueltas por la Tesorería de Santa Marta. No hay allí un especialista a quien consultar sobre la autenticidad de las monedas, y resulta improcedente encargar un funcionario para reconocerlas. La petición que formula es que se ordene a la Tesorería recibir lo recaudado con una revisión menos escrupulosa de las monedas. Esta actitud explica que quienes más rechacen la moneda macuquina sean los jefes de las oficinas de recaudación ${ }^{19}$.

Ciudadanos, funcionarios y autoridades claman al gobierno de Bogotá por medidas que pongan fin al desorden. El Administrador de Aduana propone a mediados de 1837 que se prohíba la introducción de las monedas caraqueñas, en tanto se arregla el sistema monetario nacional. Saliendo al paso a la situa-

19 Para el caso de los jefes de rentas, por cuyas manos pasan, en cálculos de abril de 1837, unos $\$ 20.000$, mucho de lo recibido es rechazado a la hora de hacer pagos o entregas. Por otro lado, el conteo de dinero en las oficinas se dilata más, pues su examen se hace más riguroso (AGN, G 400, f. 440). 
ción, el gobernador Díaz Granados toma varias medidas. A mediados de 1837 insiste con los jefes políticos para que los alcaldes y jueces de cada cantón reciban y hagan recibir toda moneda de plata "redonda o cortada que se conosca no vaciada o falsificada, que aun conserve sus respectivos signos; y que siquiera, aun que esten algo gastadas, contengan las dos terceras partes de su valor". Las penas por resistirse consisten en el pago del doble del valor de la moneda rechazada (AGN, $G 400$, f. 422 v.-423r.).

Frente a la circulación de monedas, el gobierno neogranadino mantiene determinaciones equívocas. En mayo de 1838 se ordena la revisión de todas las oficinas de hacienda, con el objeto de saber la cantidad existente de monedas con el busto de la reina española Isabel II, pues para el despacho de Hacienda su circulación no está autorizada. Pero el gobernador, en vista de que las monedas son aceptadas por el comercio, ordena que con ellas se pague a los empleados y particulares, pero con la advertencia de que no sea admitida por ninguna oficina de hacienda (AGN, G 400, ff. 420v.-422r.). A comienzos de 1839 ordena la circulación en la Provincia de toda la moneda macuquina de cruz, mejicana, cabo de barra y caraqueña, siempre y cuando no sea falsificada, las cuales deben ser aceptadas por su valor nominal en todas las ventas y en pago de todo género de deudas, tanto por particulares, compañías y comunidades como por las oficinas y tesorerías de recaudación de rentas nacionales y públicas. Aún así, Díaz Granados sigue convencido de la necesidad de llevar a cabo medidas en todo el país, pues de no verificarse, seguirían las dificultades para "llevar en orden los negocios" tanto en el nivel de las transacciones comerciales como de las oficinas nacionales" (AGN, G 399, ff. 715v.-717v.).

En el segundo tema citado, el de las importaciones, el laberinto legislativo acusa similar caos. Con la paulatina decadencia de Cartagena como puerto comercial, no solo el de Santa Marta, sino también el de Sabanilla, con más adecuadas conexiones a la desembocadura del río Magdalena, fueron fortaleciéndose lentamente a lo largo de la primera mitad del siglo XIX. Los cambios son evidentes, sobre todo, a lo largo de los años treinta, cuando Santa Marta registra una entrada de buques considerable respecto a su promedio en la década anterior. En 1835 se concedió a Santa Marta el estatus de puerto de bodegaje, de modo similar al de Cartagena. Por la misma época, Sabanilla se consolida como puerto exportador ${ }^{20}$.

Sin embargo, la consolidación del puerto de Santa Marta no se acompaña de una mejora en sus condiciones, ni de mayor atención por parte del gobierno central respecto al de 


\section{FRONTERAS}

Una constante fuente de problemas en el trabajo de la Aduana de Santa Marta es el sistema de clasificación de derechos que pagar por parte de las mercancías y productos importados. Durante los años veinte rigen cuatro sistemas de tarifas distintas: 1822, 1824, 1826, 1828 (Laffite Carles, 140). La movilidad del sistema genera incertidumbre en la aplicación de los principios e impide la consolidación de criterios al respecto; además, su interpretación se dificulta, dado que muchas de las situaciones presentadas en la Aduana no están contempladas. La evaluación de los artículos y la asignación de derechos por pagar son establecidas por la misma Aduana, lo que conduce a un agotador proceso de réplica e imputación por parte de los comerciantes ${ }^{21}$. A fines de 1832 el administrador de Aduana lo señala como un procedimiento "sumamente penoso", pues se deben hacer muchas operaciones y es fácil cometer errores. Además, la inestabilidad y los frecuentes cambios de tarifas no solo desestimulan el comercio marítimo, sino que propician el aumento del fraude ${ }^{22}$.

Una representación del comercio samario en contra de una liquidación de derechos, en marzo de 1833, da cuenta de otro aspecto problemático en el manejo de las importaciones: el desigual procedimiento en los regímenes de las aduanas de la costa Caribe:

La diversidad de ordenes y resoluciones contradictorias que se han comunicado a las aduanas hace muy dificil y expuesto todo procedimiento de estas, y aun puedo decir que no es uniforme en las de este Estado, por que en las de Cartagena y Riohacha por ejemplo, se hacen avaluos de los articulos que no tienen aforo en el arancel, o no estan comprendidos en el, cargando un $20 \%$ sobre el valor de la

Cartagena. Con más trabajo y con mayor "costo de vida" en Santa Marta, el número de empleados en Cartagena es mayor, y mayores también, sus dotaciones. Adicionalmente, Cartagena dispone de un edificio adecuado y más seguro para las operaciones de la Aduana y el control de operaciones furtivas, tal como lo resienten los comerciantes y autoridades samarias (Véase El Samario 8 de marzo de 1844, 1-2).

21 La impugnación a las liquidaciones elaboradas por la Aduana son permanentes por parte de las casas y representantes comerciales, quienes apelan ante el Presidente para reclamar sobre la manera como se determinan los derechos de importación señalando sus discrepancias en la clasificación de los objetos importados y exigiendo la devolución de los derechos cobrados "de más" (AGN, GV 208, ff. 463-465; G 386, ff. 657-660, 719-722).

22 El sistema de arancel y tarifa entonces vigente divide las mercancías en 7 clases fuera de las que pagan derecho específico. Estas clases se dividen, en la práctica, en catorce operaciones, teniendo en cuenta que los porcentajes que debe pagar la mercancía nacional o extranjera son distintos (AGN, G 389, ff. 82-84). 
factura certificada, y en esta [la de Santa Marta] solo se aumentan los costos y gastos de flete que es muy poco [...]. (AGN, G 398, f.183) ${ }^{23}$.

La ley de importaciones sancionada el 5 de junio de 1834 pretende subsanar las discrepancias anotadas. Los derechos de importación se aumentan, y las naves nacionales son eximidas del pago de los derechos de tonelada y anclaje cuando hiciesen cabotaje. En adelante, el recaudo de importación lo hará la misma Aduana y no la Tesorería, como hasta entonces (AGN, G 393, ff. 588607). A pesar de todo, la sensación entre los administradores de la aduana en Santa Marta es de confusión: no queda claro qué disposiciones se derogan y cuáles siguen vigentes. ¿Un barco venezolano es nacional o extranjero?, se preguntan, pues la misma ley considera los buques y productos venezolanos como extranjeros en algunos casos, y en otros hace diferencia entre los productos venezolanos y los extranjeros. La clasificación de los efectos importados es igualmente confusa, pues no se especifican algunas medidas ni criterios para clasificar. Baratijas, tejidos de lino o algodón y quincallería resultan ser clasificaciones equívocas y muy subjetivas para un artículo, se afirma ${ }^{24}$.

Tampoco se contempla la realidad de los tiempos requeridos en las operaciones de Aduana: descarga, traslado de la carga a la Aduana, clasificación de las mercancías, etc. Los legisladores no conocen los mecanismos reales con que funcionan las oficinas de Aduana, por ejemplo, en cuanto al tiempo que verdaderamente requiere la ejecución de procedimientos como la liquidación de derechos. La clasificación de las mercancías para el pago de derechos se complica, pues se pasa de tres a seis clases, buscando incluir productos antes no considerados. Por lo demás, las facturas de liquidación son largas y complicadas. Ciertamente, el trabajo de la Aduana se complejiza, y el tiempo que deben aguardar los comerciantes se dilata. En Santa Marta esta ley de junio de 1834, así como multiplica el trabajo de los empleados de la Aduana, al

23 La ley de importaciones de junio de 1833 modifica el sistema de liquidación de derechos, pero mantiene discrepancias relativas al pago del derecho de tonelada sobre las embarcaciones que llegan en lastre a los puertos de Riohacha y Santa Marta. En el primero se cobra a los diez días después de la llegada de un buque y en el segundo se cobra si el buque tiene carga a bordo. Una diferencia de procedimiento en dos puertos vecinos y de un mismo Estado que perjudica al propio estado, según lo ve el vicecónsul de EE. UU. en Riohacha (AGN, G 390, ff. 320-331, 393, 608-611).

24 "Muchos artículos pueden ser a la vez de la clase muebles y utensilios, o de la de mercadería o quincalla. Las tijeras y las navajas, ¿Son un utensilio de metal, $5^{\text {a }}$ clase, o una mercadería, $3^{\mathrm{a}}$ clase? Las palabras "muebles y utensilios", se estima, es demasiado lata" (AGN, G 393, f. 589). 


\section{FRONTERAS}

complicar la contabilidad, se considera perjudicial para los comerciantes, pues el pago de derechos es más gravoso que el de antes.

Otro orden de problemas relacionados con la ley de importaciones de 1834 es planteado por el administrador de la Aduana. Los productos se gravan por su función y no por su calidad intrínseca; se habla, por ejemplo, de los clavos de hierro y cobre para la construcción de buques y embarcaciones menores, o de lonas para hacer velas, pero estos mismos son productos que pueden aplicarse en otros usos. En el establecimiento de calidades ocurre que se gravan con un derecho características específicas: los jabones perfumados tienen derecho, pero llegan tipos diversos; está gravado el aguardiente de uva, pero no está prevista la entrada de otros licores. La determinación de características muy específicas en los productos por gravar siempre deja sin considerar otros del mismo tipo ${ }^{25}$.

Tanto los comerciantes como los administradores provinciales sostendrán en adelante su rechazo a los términos de la ley. El gobernador García Munive, con experiencia de varios años como administrador de la Aduana, y en el marco de un informe al gobierno sobre el arancel, lo califica como un "perfecto laberinto" que confunde tanto a funcionarios como a los comerciantes, y que solo conduce a interminables disputas entre unos y otros, y da lugar a errores que en ocasiones afectan al Tesoro y en otras, a los comerciantes. A las dificultades sobre la clasificación de los artículos se añade el problema de que el gobierno expide resoluciones parciales, esto es, para casos concretos que debe resolver (AGN, G 395, ff. 330-336).

Con ocasión del informe presentado al gobierno en marzo de 1837, el gobernador insiste en lo dispendioso de ciertas operaciones en la estructura del arancel y demanda una ley que mencione explícitamente los artículos de prohibida importación, lo cual es tanto más necesario si se considera que por entonces todavía en Europa se utiliza el nombre de Colombia confundiendo las tres repúblicas que ahora existen; de paso, se evitaría la excusa de los comerciantes extranjeros de no conocer las leyes nacionales. El tema de los artículos de prohibida importación refiere otro aspecto del problema. La ley de junio

25 Se establece, por ejemplo, un derecho para las mantas de $8 / 4$ o menos, pero la ley no dice nada de las mantas que pasan esta medida. Se excusa del pago de derechos a las máquinas e instrumentos para la explotación de minas, pero quedan sin definir cuáles son las herramientas "útiles" para la explotación minera, así como las clases de derechos de que están exceptuados (AGN, G 391, f. 442). 
de 1834 permite ingresar a Panamá artículos de prohibida importación en los demás puertos de la Nueva Granada. En aras de una uniformidad todavía precaria, se plantea también que la nomenclatura del arancel debe hacer uso del diccionario castellano y no formarse por los términos provinciales con que se conociese el artículo en una u otra región (AGN, G 395, ff. 336-339).

A lo largo de 1830 estas elites resienten la acción del Congreso como no representativa de sus intereses e iniciativas, reconocen las distintas dificultades en la conformación de un administrativo en el orden local y señalan los diversos problemas causados por la dispersión legislativa; todo ello, yuxtapuesto a las rivalidades políticas y económicas entre Mompós, Santa Marta y Riohacha, y de todas ellas respecto a Cartagena. Estos elementos constituyen el trasfondo político del conflicto de 1840 y permiten reconocer, detrás de la reivindicación de soberanía provincial, las resistencias, mediaciones y acuerdos en torno al orden institucional que propone el poder centralizador, las dificultades enfrentadas en la consolidación de esas instituciones en la Provincia, y con ello, el particular proceso de institucionalización estatal. Los aspectos tratados hasta aquí muestran que la acción de una estructura relativamente centralizada, pero con serios obstáculos para su acción unitaria, no es una anomalía, sino consecuencia del tipo de negociación que va dándose con las elites provinciales (Tilly 114).

\section{Los pueblos de la Costa reasumen la soberanía}

El errático manejo del gobierno de José Ignacio de Márquez a los levantamientos de septiembre de 1839 en Pasto, así como a la creciente oposición de "republicanos" y "liberales", configura la oportunidad política para que las tensiones expuestas, que vienen enfrentando la Provincia con el poder central, se manifiesten en forma de pronunciamientos que, en nombre del ejercicio de la soberanía de los pueblos, reivindican la forma federal y terminan en el ejercicio de la guerra.

A partir de septiembre de 1840 las Provincias de la Nueva Granada comienzan su distanciamiento del gobierno de Bogotá. Los pronunciamientos que se van sucediendo tras el de Socorro, el 21 del citado mes, al que se han unido Casanare, Tunja y Pamplona, declaran la ruptura de los vínculos de los pueblos de las provincias que los ligan con la Nueva Granada, y proclaman reasumir su soberanía. El 11 de octubre de 1840 se produce en Ciénaga, cantón de la provincia de Santa Marta, el pronunciamiento que da inicio a la Revolución de la Costa, y se reivindica con ello la forma federal de gobierno. La ciudad 


\section{FRONTERAS}

de la fistoria

Vol.13-1 / 2008

de Santa Marta secunda la iniciativa el 14 de octubre siguiente y la provincia toma el nombre de Estado de Manzanares. El general Francisco Carmona se declara jefe civil y militar del nuevo Estado.

Disuelto el pacto de unión entre las provincias que componen el territorio de la Nueva Granada, cesa, de hecho, la autoridad depositada en los individuos que ejercen el gobierno supremo en Bogotá, el mayor número de asociados recobran su soberanía y se dan reglas provisorias para gobernarse y evitar la anarquía controlando el orden público (Gaceta 9 de junio de 1841) ${ }^{26}$. Las instituciones han sido anuladas de hecho por el mismo "pueblo soberano" que las ha creado. Los vínculos que ligan las provincias granadinas a la obediencia de la constitución de 1832 han quedado disueltos una vez que, mediante actos explícitos, se ha declarado caduca aquella constitución por la voluntad popu$\operatorname{lar}^{27}$. De esta manera, cuando se da inicio a las sesiones plenarias del Congreso en mayo de 1841, en las que se posesiona como presidente el general Alcántara Herrán, entre los días 14 y 15, de las 20 provincias constitutivas que están sustraídas "del dominio de los que gobiernan en Bogotá", algunas han proclamado expresamente el sistema federal, y todas han invocado una Convención Nacional que reorganice y constituya la república ${ }^{28}$. Salvo en el punto del federalismo, las referencias son similares en todos los pronunciamientos: las razones aducidas, los propósitos impuestos y las medidas tomadas ${ }^{29}$. El

26 La tesis del gobierno en Bogotá según la cual la Constitución conserva su vigencia, al no haberse seguido los trámites definidos para su revocación y reforma, era desestimada como pueril. Contra el señalamiento de que los pronunciamientos no eran populares, se precisa que estos han sido encabezados por los notables de cada provincia; es decir, "aquellos ciudadanos influyentes que en emergencias tales representaban el público, sus necesidades, ecsijencias y medios, y á estas notabilidades, á estos ciudadanos han seguido las masas". Juan Antonio Gutiérrez de Piñerez, "Protesta del general Jefe Superior de Cartagena", Cartagena, 8 de abril de 1841 (Gaceta 21 de abril de 1841).

27 "Protesta de Juan Antonio Gómez dada en Santa Marta el 5 de mayo de 1841" (Gaceta 5 de mayo de 1841)

28 De hecho, los representantes de Antioquia, Cartagena, Mariquita, Mompós, Pamplona, Panamá, Riohacha, Santa Marta, Socorro, Tunja y Veraguas dejan de concurrir al Congreso (Arboleda 2: 7). El Congreso que sesiona no representa la voluntad popular: de las 20 provincias que formaron la república, 15 se han separado de la asociación política granadina, y ninguna habría vuelto a ella si no hubiese sido obligada por la fuerza de las armas. Del total de 1.700 .000 personas, la población cobijada por las provincias que deshicieron el pacto constituyente suman alrededor de 1.200.000. ¿Qué nación, entonces, representan políticamente los congregados de Bogotá? "Protesta del general Jefe Superior de Cartagena, Juan Antonio Gutiérrez de Piñerez, Cartagena el 8 de abril de 1841" (Gaceta 21 de abril de 1841).

29 Los pronunciamientos de Cartagena el 19 de octubre de 1840, Panamá el 18 de noviembre de 1840, Buenaventura el 28 de marzo de 1841, Popayán el 29 de marzo de 1841, y el can- 
de Santa Marta invoca la inconstitucionalidad del gobierno de Márquez y los "desaciertos" cometidos en su administración, que han dejado a la República en un "estado de disociacion i envuelta en las calamidades de la guerra civil" (Pronunciamiento).

Entre las razones que han llevado a la guerra, y que se atribuyen al gobierno de Márquez y "su conducta ministerial", se reiteran la de permitir la intervención de tropas extranjeras en las disensiones domesticas, la desmembración del territorio granadino, la simpatía que en todo el territorio produjo Obando, dada la persecución a la que fue sometido, y el desconocimiento del derecho de gentes; esto es, la calificación que el gobierno de Bogotá hace de la reacción popular como facciosa. Sobre esto último la situación es clara: la mayoría de provincias levantadas no constituyen una facción. El gobierno de Bogotá está desconociendo la legitimidad de "una parte de la nación" que se ha sustraído de la obediencia del gobierno y se organiza, administra justicia y ejerce otros actos de soberanía. Estas acciones no son propias de facciosos, sino de una fracción que con ellos se constituye en una persona moral con el goce de las prerrogativas de una nación. Márquez y su gobierno, por el contrario, siguen persiguiendo, juzgando y haciendo fusilar como facciosos a los disidentes que caen prisioneros de guerra, desconoce el derecho que los favorece y, con todo ello, no hacen más que extender la guerra y mantenerla (Gaceta 31 de marzo de 1841 y 7 de abril de 1841).

El propio general Carmona tiene oportunidad de explicar a mediados de 1841 las razones que han dado lugar al "trastorno general de la república granadina" y obligado a los pueblos de la Nueva Granada, y en particular a las provincias de la Costa, a "sustraerse del dominio de los que gobiernan en Bogotá y proclamarse por el sistema federal invocando una Convención Nacional que reorganice y constituya la república ${ }^{30}$. Señala, así mismo, la no adecuación de la Constitución de 1832 y del régimen centralista a las demandas y necesidades de los pueblos, entre otras razones, porque se trata de "una constitución festinada en momentos en que no habían calmado las pasiones agitadas por anteriores disturbios" y muy pronto se reconocerá que "ni era aceptable en el

tón del Atrato el 7 de mayo de 1841 fueron reproducidos por la Gaceta del Estado de Manzanares en diferentes números. La similitud en las actas se explicaría "porque los modelos fueron copias enviadas de Bogotá por un club revolucionario que allí existía compuesto de los primeros y más distinguidos liberales", encabezado por Vicente Azuero. En versión de Restrepo, puede hablarse de un plan revolucionario de la oposición (191, 389-391).

30 "Carta del Gral. Carmona al Secretario de relaciones exteriores de Venezuela. Ocaña, 3 de enero de 1841" (Gaceta 2 de junio de 1841). 


\section{FRONTERAS}

de la fistoria

Vol.13-1 / 2008

todo ni practicable en mucha parte". Las leyes que se fueron acumulando año a año en cada legislatura

Participaban en general de los defectos de aquel código del cual emanaban; y así es que en breve tiempo jerminó y creció un descontento general en las masas que por instinto buscaban como siempre el mejoramiento: así ha marchado la República por muchos años y asi habia continuado sufriendo los males de una pésima organización social por evitar los males horrorosos de la guerra civil, si una administración vindicativa, apasionada, débil e inecta, no hubiese en estos ultimas exasperado a los mas pacientes y provado que el espíritu de vertigo que se ha apoderado de los que gobiernan en Bogotá no deja ya al pueblo otro recurso que el santo derecho de insurrección. Derecho peligroso, terrible, tremendo, pero derecho único á que ha podido apelar en tamaño conflicto.

La iniciativa autonomista en la interpretación de Carmona es claramente elitista. Los notables y "aquellos interesados en la conservación de la paz y el orden", procurando acallar el clamor de los pueblos, aguardaron "en silenciosa calma" a que el tiempo y las reformas paulatinas a las instituciones "perfeccionaran el sistema político", pero, dado que la constitución vigente no ha garantizado el mejoramiento de los pueblos, el razonamiento conduce a defender el federalismo como lo más adecuado a las expectativas de progreso de las provincias:

[...] la Nueva Granada encierra en su vasto territorio provincias tan difíciles de unir bajo un sistema estrictamente centralista y sujetas á leyes universales, que sería lo mismo que pensar que una misma ley pudiera gobernar al Francés y al Ruso. Nosotros necesitamos brasos que abatan nuestros inmensos bosques y mientras los pueblos de la Costa vean en todo hombre de cualquiera creencia un compañero que los ayude en esta hermosa tarea, el fanatismo del interior los rechaza como hérejes. Necesitamos cultivar las plantas mas valiosas de nuestro suelo que estaban por una imitación ridícula del sistema colonial bajo un vergonzoso monopolio. Deseamos dar franquicia á nuestros metales preciosos y últimamente adelantar en la carrera de la civilización y el progreso sin vernos sugetos á la miserable tutela en que nos ha tenido un pueblo que ya por que no conoce bien sus propios intereses ó ya por que se encuentra mas atrasado, no quiere romper los diques que han de desarroyar nuestra industria nuestro comercio y nuestra riqueza.

El Estado del Manzanares llega a reunir a las provincias de Santa Marta, Cartagena, Riohacha y Mompox como Estados confederados, pero aún así 
se concibe como un Estado integrante de la nación. Cuando el Estado busca dotarse de instituciones políticas lo hace pensando en su carácter provisional, a la espera de un pacto político. De modo que con ocasión de la Asamblea de Diputados para el Estado, planeada para realizarse en abril de 1841, y no obstante impulsarse su organización, se tiene en perspectiva la reunión de una gran Convención que "arreglase los intereses y gobierno de los cuatro Estados Confederados"31, con lo cual, está claro que no se trata de una separación de carácter permanente que amenace la unidad política neogranadina ${ }^{32}$.

El desarrollo adverso que sufre la Revolución de la Costa es bastante conocido. Tras las sucesivas derrotas del general Obando, del coronel Manuel González y de Reyes Patria, así como del coronel Salvador Córdoba, las fuerzas del Ejercito Unido de la Costa sucumben el 1 de abril de 1841 en Tescua. Y aunque Carmona, al regresar a Santa Marta el 26 del mismo mes, emprende la reorganización de su fuerza y dispone un sitio a Cartagena, la sucesión de contra- pronunciamientos y los avances del general Pedro Alcántara Herrán sobre las distintas poblaciones de la costa atlántica, terminan por descalabrar la fugaz experiencia federal. Ya en Sitionuevo, y de por medio varias negociaciones y conversaciones, Alcántara Herrán expide el 11 de febrero de 1842 una amnistía general, restablece a Pedro Díaz Granados como gobernador y, finalmente, llega a Santa Marta el 24 del mismo mes. En la Costa Caribe, más allá de la retórica con que se exponen razones y propósitos para el recurso a las armas, la experiencia del Estado del Manzanares, aunque efímera, da ocasión a los dirigentes políticos para manifestar su coherencia con el federalismo.

31 Los cuatro gobiernos acuerdan la reunión de la Asamblea en la villa de Barranquilla. Con ocasión de las elecciones se otorga derecho al voto a todos los mayores de 18 años (Gaceta 31 de marzo de 1841).

32 Ante la solicitud del agente consular francés en Santa Marta, quien a fines de abril de 1841 reclama el cumplimiento del tratado de comercio entre Francia y la Nueva Granada, Juan Antonio Gómez, en su calidad de Jefe Superior, al tiempo que lo garantiza reitera que lo hace porque "[siendo] los deseos del pueblo del Manzanares conservar la unidad política de la nación granadina bajo la forma federal, es tambien su voluntad mantener aquellos actos que se refieran á las relaciones internacionales de la República con los pueblos extranjeros"(Gaceta 12 de mayo de 1841). 


\section{Bibliografía}

\section{Fuentes primarias}

Archivo General de la Nación, Colombia (AGN):

Gobernaciones $(G)$.

Gobernaciones Varias $(G V)$.

Biblioteca Nacional de Colombia, Colombia (BN).

Fondo Quijano $(F Q)$.

\section{Prensa}

El Amigo País [Santa Marta, Colombia].

Gaceta del Estado del Manzanares [Santa Marta, Colombia].

\section{Fuentes secundarias}

Arboleda, Gustavo. Historia Contemporánea de Colombia, t. 1. Bogotá: Librería colombiana de Camacho Roldán y Tamayo; Casa editorial de Arboleda y Valencia, 1919.

Bell Lemus, Gustavo. Política regional y la formación del Estado nacional: la costa caribe de Colombia en los primeros cincuenta años de independencia, 1810-1860. Barranquilla: Fundación para la promoción de la investigación y la tecnología; Banco de la República, 1997.

Chiaramonte, José Carlos. "La formación de los Estados nacionales en Iberoamérica". Boletín del Instituto de Historia Argentina y americana "Dr. Emilio Ravignani". 3 serie: 15 (1997).

—. "Estado y poder regional: constitución y naturaleza de los poderes regionales". La construcción de las naciones latinoamericanas 18201870. París: UNESCO, 2003. Vol. 6 de Historia general de América Latina. Ed. Josefina Z. Vázquez. 9 vols. 
Gilmore, Robert Louis. El federalismo en Colombia 1810-1858, t. 1. Bogotá: Sociedad Santanderista de Colombia - Universidad Externado de Colombia, 1995.

González G., Fernán. "La guerra de los supremos". Para leer la política. Ensayos de historia politica colombiana, por González. T. 2. Bogotá: Cinep, 1997.

González, Margarita. "Aspectos económicos de la administración pública en Colombia: 1820-1886". Anuario de Historia social y de la cultura 13-14 (1985-1986): 63-89.

Laffite Carels, Christiane. La costa colombiana del Caribe (1810-1830). Bogotá: Banco de la República, 1995.

López-Alves, Fernando. La formación del estado y la democracia en América Latina. Bogotá: Norma, 2003.

Martínez Garnica, Armando. "El movimiento histórico de las Provincias Neogranadinas". Anuario de Historia Regional y de las Fronteras 6 (2001): 3-57.

Pronunciamiento de Santa Marta. Santa Marta: Imp. de Locarno i Guerrero, 1840.

Restrepo, José Manuel. Historia de la Nueva Granada, t. 1. Bogotá: Cromos, 1952.

Tilly, Charles. Coerción, Capital y Estados Europeos. Madrid: Alianza, 1992.

Sourdis Nájera, Adelaida. "Ruptura del estado colonial y tránsito hacia la república 1800-1850". Historia Económica y social del Caribe colombiano. Ed. Adolfo Meisel Roca. Bogotá: Uninorte-Ecoe, 1994.

Uribe de Hincapié, María Teresa y Liliana María López Lópera. Las palabras de la guerra. Un estudio sobre las memorias de las guerras civiles en Colombia. Medellín, Colombia: Universidad de Antioquia; Corporación Región; La Carreta, 2006.

Fecha de recepción: 29 de noviembre de 2007.

Fecha de aprobación: 15 de mayo de 2008. 